\title{
Detection of free-ranging West Indian manatees Trichechus manatus using side-scan sonar
}

\author{
Daniel Gonzalez-Socoloske ${ }^{1,3, *}$, Leon D. Olivera-Gomez ${ }^{2}$, Robert E. Ford ${ }^{1,4}$ \\ ${ }^{1}$ Dept. of Earth and Biological Sciences, Loma Linda University, 11065 Campus Street, Loma Linda, California 92350, USA \\ ${ }^{2}$ División Académica de Ciencias Biológicas, Universidad Juárez Autónoma de Tabasco, Carretera Villahermosa-Cardenas \\ Km 0.5, C.P. 86150, Villahermosa, Tabasco, Mexico \\ ${ }^{3}$ Present address: University Program in Ecology, Duke University, PO Box 90329, Durham, North Carolina 27708, USA \\ ${ }^{4}$ Present address: Center for GIS Training and Remote Sensing, National University of Rwanda, PO Box 212, Huye, Rwanda
}

\begin{abstract}
Turbid and tannin-stained waterways are difficult habitats to study and present problems with respect to the management of aquatic fauna, and especially of endangered and cryptic animals such as manatees Trichechus spp. Linnaeus. Throughout much of the range of the extant trichechid species ( $T$. inunguis, $T$. manatus, and $T$. senegalensis), the scientific approaches that are used successfully to document the status of the Florida subspecies (T. m. latirostris) are not feasible, due either to constraints associated with habitat or to the high costs involved. We examined the use of side-scan sonar as a novel way to acoustically detect free-ranging West Indian manatees (T. m. latirostris and T. m. manatus), and evaluated the effectiveness of the technology under various environmental conditions. Blind transects, where one observer only looked at the sonar, were conducted in Mexico and Florida to confirm that manatees could be detected and to determine a preliminary manatee detection rate for the sonar unit. Quality sonar images were produced under most environmental conditions examined, provided that ambient water movement was low. Manatees were successfully detected laterally up to $18 \mathrm{~m}$, and the best acoustic images were produced when the animals were stationary and oriented parallel to the boat. Preliminary detection was 81 and $93 \%$ in Florida and Mexico, respectively. We conclude that over limited areas, and under certain environmental conditions, side-scan sonar is a cost-effective option to accurately detect manatees and provide important information for conservation decisions. Like all survey techniques, it has limitations, but its unique advantages will be a welcomed alternative to aerial surveys and visual boat surveys of opaque waterways.
\end{abstract}

KEY WORDS: Acoustic detection · Manatees · Turbid waterways $\cdot$ Trichechus manatus $\cdot$ Side-scan sonar $\cdot$ Florida $\cdot$ Mexico $\cdot$ Honduras

\section{INTRODUCTION}

Studying the aquatic fauna of estuaries, lagoons, and turbid rivers is challenging because of the difficulty of observing animals in murky waters. The narrow winding shape of riverine habitats and overhanging vegetation increases the challenge. Mildly social, cryptic species, such as manatees Trichechus spp., which use these waterways throughout most of their range, are particularly difficult to study because they spend large amounts of time below the surface where they cannot be visually de- tected (Reynolds \& Powell 2002) and, when they do surface to breathe, they often only briefly expose the tip of their muzzle. In addition, in areas with traditionally high hunting pressure, manatees may avoid human presence or may exhibit greater nocturnal activity (Rathbun et al. 1983). The 2 main methods currently used by most researchers to detect manatees are aerial surveys and boat/land-based surveys (Lefebvre et al. 1995, Aragones et al. 1997), both of which rely on visual detections and are better suited for relatively clear, shallow water in coastal marine areas (Ackerman 1995). Aerial 
surveys provide rapid coverage of habitat over large spatial scales, but can be costly, dangerous, and have low detection rates, especially in inland areas where water clarity is low and visibility often obstructed by overhanging vegetation. Boat and land-based surveys are comparatively inexpensive, but cover small spatial scales, are very labor intensive, and have very low detection rates, especially in areas where manatees are hunted. Throughout much of their range it is very difficult to detect manatees and thus to obtain reliable estimates of their abundance and habitat preferences. Only areas with primarily clear coastal marine water (i.e. Belize, Caribbean coast of Mexico, Puerto Rico; Lefebvre et al. 2000, Morales-Vela et al. 2000) or where obligatory seasonal clustering occurs due to manatees' inability to tolerate low temperatures (i.e. Florida; Garrott et al. 1994, Craig \& Reynolds 2004) have been reliably surveyed. In the present study, we examined the effectiveness of using side-scan sonar as an alternative method to detect and survey manatees in the wild.

Active acoustic detection, using single or multi-beam echo sounders or other sound navigation and ranging (SONAR) systems, has been used as a tool to study fish densities (Gerlotto et al. 2000) and some swimming and schooling behaviors (De Robertis et al. 2003, Rose et al. 2005). The target strength, defined as the proportion of sound that is reflected by the target back to the array, has been measured for several marine mammals, including bottlenose dolphins Tursiops truncatus (Au 1996), humpback whales Megaptera novaeangliae and northern right whales Eubalaena glacialis (Miller et al. 1999, Miller \& Potter 2001), and recently the Florida manatee Trichechus manatus latirostris (Jaffe et al. 2007). Au (1996) found that the acoustic target strength of dolphins was greatest in the location of the lungs and was largely dependant on body orientation. Manatees have large elongated lungs that are positioned dorsally (Rommel \& Reynolds 2000), providing an excellent acoustic target.

Most of the early attempts to develop sonar equipment that could reliably detect manatees were conducted on animals in captivity and met with minimal success. Some of the major problems encountered during experiments were scatter, sonar shadowing, and reduced sonar resolution (summarized by Dickerson et al. 1996). Building on these early experiments, Dickerson et al. (1996) tested the efficacy of 10 different, more advanced sonar units, with the aim of creating a manatee detection system in order to prevent manatee deaths in canal locks. Dickerson et al. (1996) concluded that, while it was possible to detect manatees, the acoustic reflection was not consistent and at times no acoustic reflection was detected.

Recently, Jaffe et al. (2007) measured the acoustic reflectivity of the Florida manatee by experimenting with a detection frequency of $171 \mathrm{kHz}$ on captive animals and by analyzing animal tissue to predict reflectivity. Jaffe et al. (2007) reported that, while the majority of the reflections from live animals were between -32 and $-35 \mathrm{~dB}$, a substantial portion were below $-48 \mathrm{~dB}$, which was their detection threshold due to ambient noise. In addition, Jaffe et al. (2007) observed that many times an acoustic reflection was not observed in spite of a manatee crossing the sonar beam. However, the previous hypothesis that manatee skin acted as an acoustic sink was ruled out based on the tissue analysis (Jaffe et al. 2007). Jaffe et al. (2007) concluded that the animal skin may act as a specular reflector at the frequency tested, reflecting the acoustic signal at an unobservable angle and, therefore, not being a reliable frequency for detection. This phenomenon may explain why previous efforts to detect manatees in the wild with sonar have had mixed success (Dickerson et al. 1996).

Our goals were to develop a technique that could be used to reliably detect manatees in locations where they are difficult to see through the water and to monitor manatees over a relatively large area without the animals having to 'cross' the beam. All previous attempts to detect manatees with sonar have used stationary echo-sounder systems (Dickerson et al. 1996, Jaffe et al. 2007). While some scanning systems have been tested (rotating $360^{\circ}$ ), they work under the same principle of detecting a change in reflectivity against a constant background. We used side-scan (or lateral scanning) sonar, which produces an image of the acoustic signal as it moves in a linear direction. Sidescan sonar has traditionally been used to observe seafloor structures, including underwater objects (Dura et al. 2004). The advantage of side-scan sonar is that, under optimal conditions, it creates a picture-like image of the bottom substrate, as well as imaging objects on the surface and in the water column (Kenny et al. 2003).

We tested side-scan sonar in a variety of manatee habitats and environmental conditions to determine its usefulness in studying manatees in the wild and estimated a preliminary detection rate for the sonar unit by conducting targeted surveys where manatees could be counted visually. We conclude that side-scan sonar is a valuable tool that will assist scientists and managers in documenting the distribution and habitat use of manatees in complex waterways. The present study is the first to apply side-scan sonar techniques to detect and survey manatees.

\section{MATERIALS AND METHODS}

Study sites. Three locations were selected to test the effectiveness of side-scan sonar, each representing inland habitats used by manatees Trichechus manatus. Two of these locations (Florida and Mexico) were cho- 
sen because manatees could be visually detected with relative ease, proving ideal places to determine if they could be detected with the sonar unit. The remaining site (Honduras) represented a location where manatees are known to occur, but visual detection is extremely difficult.

Honduras: Tests were conducted in Cuero y Salado Wildlife Refuge (CySWR), which is located on the northern coast of Honduras ( $\left.15^{\circ} 46^{\prime} 30^{\prime \prime} \mathrm{N}, 87^{\circ} 3^{\prime} 25^{\prime \prime} \mathrm{W}\right)$ and has been identified as an important area for manatees (Rathbun et al. 1983, Gonzalez-Socoloske 2007). CySWR consists of a series of rivers, canals, and lagoons, several of which have access to the Caribbean Sea. Water visibility is very low, due to turbidity, from both sediments and tannins. This site was primarily used to determine the effectiveness of the sonar unit under various environmental conditions.

Florida: Taking advantage of the natural winter aggregations of Florida manatees, tests were conducted in Crystal River, Florida, USA (28 53' 20" N, $82^{\circ} 35^{\prime} 35^{\prime \prime} \mathrm{W}$ ), which has long been identified as an important wintering site for manatees due to the naturally occurring warm water discharges (Kochman et al. 1985, Langtimm et al. 1998). The number of manatees that use Crystal River during the cold winter months has grown from the 63 individuals initially identified in the 1960s (Hartman 1979) to $>400$ that use it today (Reep \& Bonde 2006). We focused our testing in areas where the water was clear and lateral distances of manatees from the boat and body orientations could be determined. The areas within Crystal River that we utilized were shallow (1 to $5 \mathrm{~m}$ ), so that the bottom substrate was visible and all manatees within the lateral range of the sonar unit could be detected visually.

Mexico: Tests were conducted in Laguna de las Ilusiones $\left(18^{\circ} 0^{\prime} 0^{\prime \prime} \mathrm{N}, 92^{\circ} 55^{\prime} 59^{\prime \prime} \mathrm{W}\right)$ in Villahermosa, Tabasco. We selected this landlocked lagoon because of the relatively small area $\left(2.7 \mathrm{~km}^{2}\right)$ with a known population of manatees $(\sim 18)$ and its dark shallow waters ( 1 to $3 \mathrm{~m}$; L. D. Olivera-Gomez unpubl. data). More importantly, we could determine the location of manatees by following the bubble trails released from the sediment by manatees moving along the bottom. Such indirect evidence allowed us to provide an independent estimate of the number of manatees in the immediate area.

Equipment and interpretation of side-scan images. We used a transom-mounted Humminbird ${ }^{\circledR}$ 987c SI fishing system (Johnson Outdoor), powered by a $12 \mathrm{~V}$ deep-cycle marine battery. This quad-beam system is equipped with 2 narrow lateral beams producing at 262 and $455 \mathrm{kHz}$ and 2 vertical (echo sounder) beams producing at 200 and $50 \mathrm{kHz}$ (Fig. 1A). One or both
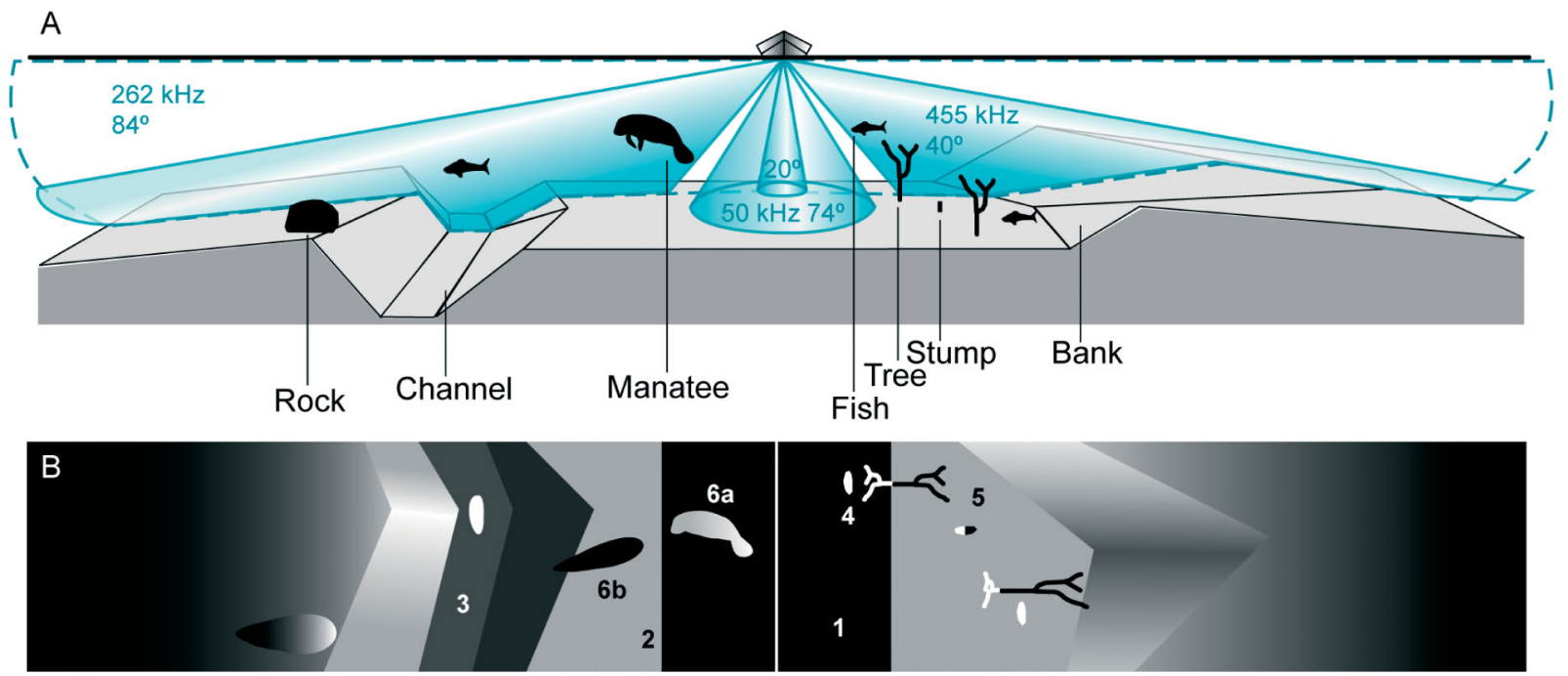

Fig. 1. Humminbird $987 \mathrm{c}$ side-scan sonar beams and interpretation of acoustic image. (A) The unit is equipped with 2 narrow lateral (side) beams of $262 \mathrm{kHz}$ ( $84^{\circ}$ coverage angle indicated by dashed line) and $455 \mathrm{kHz}\left(40^{\circ}\right.$ coverage angle indicated by solid line) and 2 echo-sounder beams of $200 \mathrm{kHz}\left(20^{\circ}\right.$ coverage angle indicated by center cone) and $50 \mathrm{kHz}\left(74^{\circ}\right.$ coverage angle indicated by outer cone). (B) The acoustic signal is displayed in a conveyer belt fashion, with the latest response as the top horizontal line. As the boat moves in a linear direction new sonar lines are added. The components of the acoustic image consist of the water column (1), which appears as a dark area between the midline and the bottom return (2). Channels (3) appear darker because of the lack of an acoustic reflection. Objects, such as fish (4) in the water column appear bright white. Objects on or near the bottom produce a shadow (5) because of the blocked signal. Shadows are more indicative of the exact shape of the object than the actual acoustic reflection. A manatee Trichechus manatus in the water column (6a) would presumably produce a reflection not as bright as a fish, but would have a large shadow (6b) associated with it, from the area of the sonar beam blocked by the body of the manatee. Image modified from Gonzalez-Socoloske (2007) 
vertical beams can be operated simultaneously with the lateral beam, while only 1 lateral beam frequency can be operated at a time. The echo-sounder beam provided a continuous depth reading during sideimaging. The unit was equipped with a built-in GPS (global positioning system) receiver for accurate location and time, and the sonar transducer was equipped with a thermometer for surface water temperature.

Side-scan sonar images were displayed on a $17.8 \mathrm{~cm}$ screen and were captured by using screen capture software designed by the manufacturer as a promotional tool. Screenshots were saved in bmp format on a secure digital (SD) memory card for further analysis. Along with the sonar image, screenshots recorded boat speed, geographical coordinates, surface water temperature, date, time of day, and water depth at the time of the screen capture. Data produced by the side-scan sonar were converted from imperial to metric units for analysis.

Screenshots consist of a left and right side, each corresponding to the acoustic reflection of the right and left side beam. The water column appears as a black (or blue if color setting is on) area from the central line to the substrate bottom (Fig. 1B). Objects in the water appear white and cast a black shadow on the bottom. Denser objects appear brighter than less dense objects; thus, rocks and coral give a stronger response than sand and clay bottoms. Similarly, fish appear much brighter than manatees, likely due to the differences in the skin density. Bottom topography is evident from the shadows and acoustic reflection gradient (Fig. 1B). Shadows, created by objects blocking the acoustic beam, are used to determine shape and form of objects and were often useful for helping identify and interpret the actual acoustic reflection from the object (Fig. 1B).

Effectiveness under various environmental conditions and manatee habitats. We tested side-scan sonar under various weather conditions (rain, moderate wind, full sun, and cloud cover), various water surface conditions (very calm to choppy), during different times of day (night and day), under different water clarity conditions (clear, turbid, and tannin-stained), and with different scanning methods (linear or rotational) to determine its usefulness as a survey tool in the field. These experiments were all conducted in Honduras, with the exception of the experiments conducted in clear water in
Florida (Table 1). The scanning method experiments consisted of comparing sonar images produced by linear trajectories and stationary tests, where the side-scan sonar transducer, the device emitting the acoustic signal, was routed $360^{\circ}$. Water surface condition was qualitatively determined, where calm was characterized by a flat, still surface with no ripples or current, moderate having some current and small waves, but no white crests visible, and choppy where waves caused by wind or currents were large enough to produce white crests. Water clarity was classified as follows: clear water - environments where we could see the bottom substrate; turbid water - environments with large amounts of debris (sediment) in the water column obstructing the bottom, and; tannin-stained waters - environments that had relatively little turbidity, but where the water was opaque and the bottom was not visible. Sonar images were also qualitatively ranked based on the clarity of the acoustic image, where 1 designated poor images in which the bottom substrate could not be discerned, 2 designated images that were discernable, but still had some interference, and 3 designated images that had no interference.

Detecting manatees with sonar. To determine if manatees could be detected accurately with side-scan sonar, tests were conducted in both Florida and Mexico by passing alongside wild manatees at a known lateral distance from the boat, estimated visually, and observing the acoustic image that was produced (Table 1). All trials were run using the $200 \mathrm{kHz}$ echosounder beam and 262 or $455 \mathrm{kHz}$ lateral beams to ensure that frequencies were well above the known hearing range of manatees.

Determination of a preliminary manatee detection rate. To determine a preliminary detection rate of manatees with side-scan sonar we conducted blind transects in both Florida and Mexico (Table 1). Blind transects consisted of the boat driver locating manatees and slowly ( 3 to $6 \mathrm{~km} \mathrm{~h}^{-1}$ ) navigating past them within the predetermined distance of $12 \mathrm{~m}$, while the 'blind' sonar observer detected them only by looking at the sonar image. Verbal confirmation was given when a manatee was detected by the sonar observer who indicated on which side of the boat the animal was and gave its approximate distance from the boat (estimated from the

Table 1. Summary of experiments with side-scan sonar and study locations. SM: scanning method; E: detection experiment; DR: detection rate. W: weather condition; WS: water surface condition; TD: time of day; WC: water clarity

\begin{tabular}{|lccc}
\hline Study site & Date & Methods & Conditions tested \\
\hline Cuero y Salado Wildlife Refuge, Honduras & 21-27 Jun 2005 & SM & W, WS, TD, WC \\
Crystal River, Florida, USA & 29 \& 31 Jan 2006 & E, DR & WC \\
Laguna de las Ilusiones, Tabasco, Mexico & 22-23 Mar 2006 & E, DR & \\
\hline
\end{tabular}


preset maximum lateral detection distance in the sonar unit). In Florida, manatee body orientation and association with a calf was recorded by a third observer. During the Florida trials, manatees were only detected on the left side of the vessel, because the sonar image screen was modified to include only the left side, due to the distortion produced by the outboard motor located to the right of the transducer. The driver noted if the detection was correct or not without informing the observer. Communication was resumed at the end of each blind transect. All blind transects were conducted during a single session and under similar water surface conditions (calm or moderate). In Mexico, a group of 3 manatees was located in the lagoon, presumably representing a mother and 2 different aged calves (determined visually by the different sizes of the muzzles and the close association). After visual confirmation, the same 3 individuals were passed repeatedly from different sides and lateral distances, following the individual bubble trails they created. In both Florida and Mexico, care was taken not to harass manatees by chasing them or passing over them. We did not conduct detection rate transects in Honduras, because of the difficulty of confirming the presence of manatees visually.

\section{RESULTS}

Good sonar images were produced under conditions where the water was not moving rapidly (Table 2). Attempts to produce good sonar images by rotating the

Table 2. Summary of results from experiments with side-scan sonar. Image scores (1: poor/unreadable; 2: intermediate;

3: good) represent the mode for each sample size (n)

\begin{tabular}{|lcc|}
\hline & Image score & $\mathrm{n}$ \\
\hline Water clarity & 3 & 38 \\
Clear & 2 & 11 \\
Turbid & 3 & 19 \\
Tannin stained & & \\
Weather condition & 2 & 4 \\
Rainy & 2 & 6 \\
Windy & 3 & 11 \\
Sunny & 3 & 9 \\
Cloudy & & \\
Water surface condition & 3 & 15 \\
Calm & 2 & 8 \\
Moderate & 1 & \\
Choppy & & 17 \\
Time of day & 3 & 13 \\
Day & 3 & 30 \\
Night & & 9 \\
Scanned method & 3 & \\
Linear & & \\
Rotational & 1 & \\
\hline
\end{tabular}

transducer were unsuccessful (Table 2). Optimal conditions for the best image clarity were produced when traveling in a straight line at speeds of 2.5 to $7.0 \mathrm{~km} \mathrm{~h}^{-1}$. The lateral range of the sonar that produced the best results was between 10 and $15 \mathrm{~m}$, although manatees Trichechus manatus could still be distinguished at $18 \mathrm{~m}$. Optimal beam frequency, sonar sensitivity, chart speed, and noise filter depended on the water and environmental conditions.

Visual confirmation of manatee detection by the side-scan sonar was attained in Florida and Mexico (Fig. 2). Manatees were successfully detected in both the water column and on the bottom substrate (see Supplement 1 for additional sonar screenshots, available at http://www.int-res.com/journals/suppl/n008p249_ app.pdf). Under optimal conditions, direction of travel and body orientation could be determined. The strongest acoustic reflection from manatees was from the dorsal area, where the elongated lungs are located. Calves could be identified in the sonar image by the relatively smaller size and the continual proximity after multiple passes. The presence of the active sonar unit appeared to have no negative influence on the behavior of wild manatees.

Fourteen blind transects were conducted in Crystal River, in which 52 manatees were passed laterally (Table 3). Of those, 42 (81\%) were detected correctly by the blind observer using side-scan sonar. The blind observer also accurately detected the lateral distance of the animal from the boat.

Twenty-nine blind transects were conducted in Laguna de las Ilusiones (Table 3). Both the right and left sonar beams were used. Twenty-seven visually detected manatees were passed on the right side, and 15 , on the left, for a total of 42 animals available for acoustic detection. Of these, the blind observer correctly detected and determined the lateral distance from the boat for 24 (89\%) of the animals on the right side and for $15(100 \%)$ on the left side, for a total of 39 (93\%) confirmed acoustic detections (Table 3).

\section{DISCUSSION}

Commercially available side-scan sonar units like the Humminbird models used in this study produce picture-like images of the bottom substrate and objects in the water column from the acoustic reflection. In our trials, the best images were produced in calm or moderate waters (with small waves or minimal currents), traveling in a linear direction at from 2.5 to $7.0 \mathrm{~km} \mathrm{~h}^{-1}$. Water clarity, time of day, and other environmental conditions had little effect on the quality of the sonar images produced, with the exception of surface water movement. Images produced in the clear Florida waters were at 


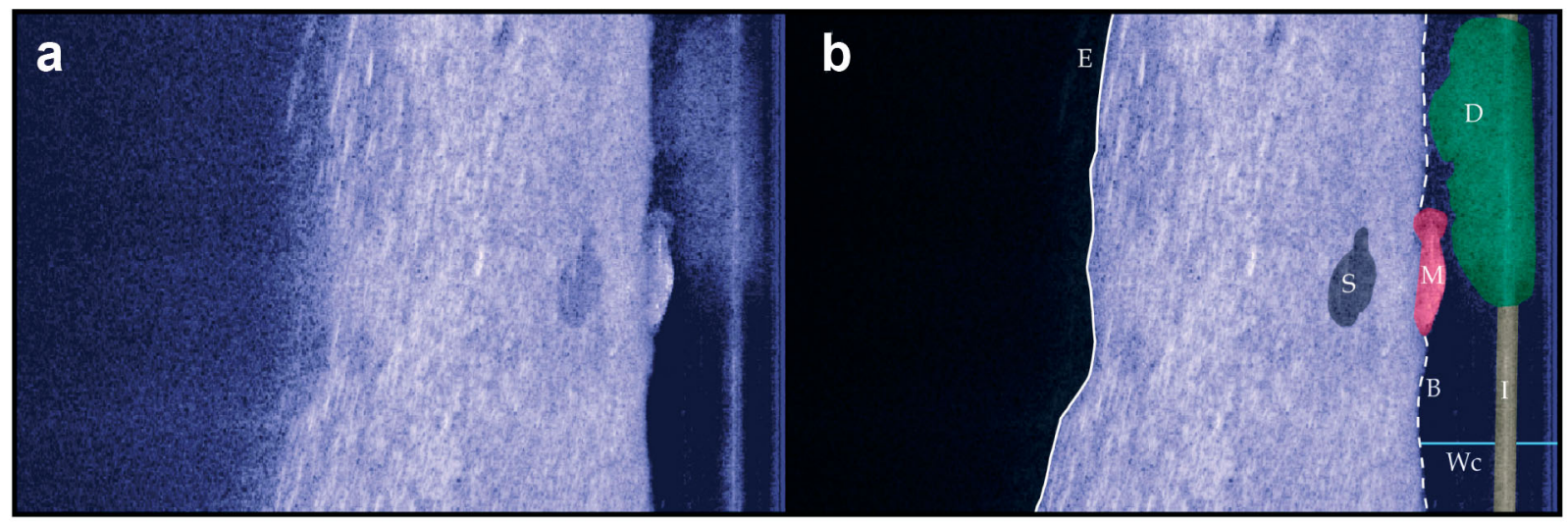

Fig. 2. Trichechus manatus. Representative screenshots of T. manatus detected by side-scan sonar. Side-scan and echo-sounder beam frequencies were producing at 262 and $200 \mathrm{kHz}$, respectively. (a) Screenshot of a single adult manatee oriented parallel to the boat, swimming in the opposite direction near the bottom of the river. Crystal River, Florida, water depth $2.13 \mathrm{~m}$, boat speed $3.5 \mathrm{~km} \mathrm{~h}^{-1}$, left side of the boat only, side-scan sonar range $12.2 \mathrm{~m}$. (b) Digitally enhanced interpretation of Panel (a). Dashed white line represents the junction between the water column (Wc) and the bottom response (B); solid white line represents the junction between the bottom response (B) and the shore (E). The water column (Wc) contains a sediment plum or debris (D) and a straight line of interference (I) caused by the on-board motor to the left of the side-scan sonar transducer. Note the gap between the acoustic reflection of the manatee $(\mathrm{M})$ and the shadow $(\mathrm{S})$, indicating that the animal was not in contact with the bottom substrate. The dark area on the far left represents the shore (thus no acoustic reflection). The bottom substrate begins at the bottom response (B) and ends at the shore edge (E)

times not as clear as those produced in the turbid and tannin-stained waters of Honduras and Mexico. This may be explained by the lack of a strong current in the clam lagoon in Villahermosa, Mexico. In some cases, flowing water caused sediment to stir up and cloud the image. Similarly, increased wind caused the water surface to become choppy, which, in turn, distorted some sonar images. In addition, it was very difficult to survey in a straight line in Crystal River, Florida, because of the heavy boat traffic and the narrowness of the river, which affected the quality of the images produced.

Manatees Trichechus manatus were accurately detected in both Florida and Mexico. There was no noticeable behavioral response to the sonar by manatees, and it appears likely that the instruments produced at frequencies well above $(>200 \mathrm{kHz})$ the

Table 3. Trichechus manatus. Results for blind transects (trials) in Crystal River, Florida, USA and Laguna de las Ilusiones, Tabasco, Mexico

\begin{tabular}{|lcccc|}
\hline & $\begin{array}{c}\text { No. of } \\
\text { trials }\end{array}$ & $\begin{array}{c}\text { Manatees } \\
\text { passed }\end{array}$ & $\begin{array}{c}\text { Manatees } \\
\text { detected }\end{array}$ & $\begin{array}{c}\text { Distance from } \\
\text { boat }(\mathrm{m})\end{array}$ \\
\hline Crystal River & & & & \\
$\mathrm{n}$ & 14 & 52 & $42(81 \%)$ & \\
Mean \pm SD per transect & & $4 \pm 3$ & $3 \pm 3$ & $2.5 \pm 1.2$ \\
Range & & $0-10$ & $0-8$ & $0-7$ \\
Laguna de las Ilusiones & 29 & 42 & $39(93 \%)$ & \\
$\mathrm{n}$ & & $1 \pm 1$ & $1 \pm 1$ & $2.2 \pm 2.7$ \\
Mean \pm SD per transect & & $1-3$ & $0-3$ & $0-10$ \\
Range & & & & \\
\hline
\end{tabular}

known hearing range of 6 to $20 \mathrm{kHz}$ for manatees (Gerstein et al. 1999). The strongest acoustic reflectivity correlated with the area of the lungs, in accordance with results from experiments on dolphins (Au 1996). Manatees appear to give a much weaker acoustic reflection than that recorded for dolphins (Au 1996, Jaffe et al. 2007). The reason for this difference is unclear, but may be due to the differences in skin density (Kipps et al. 2002).

Manatee body orientation in relation to the track line greatly influenced their acoustic reflectivity, as also noted by Au (1996) with dolphins. Manatees that were parallel to the boat (perpendicular to the sonar beam) gave the best acoustic reflection. When animals were perpendicular to the boat (parallel to the beam), the acoustic reflection was not as evident or, at times, was missing altogether; however, a characteristic acoustic shadow was always produced. This lack of acoustic reflectivity was also noted by previous attempts to detect manatees with sonar (Dickerson et al. 1996, Jaffe et al. 2007). The presence of the characteristic shadow produced by the manatee blocking the sonar beam presents an advantage of side-scan sonar over other acoustic attempts.

It is possible that manatees in clear water behave differently towards boats than those in turbid and tanninstained water. In Florida, manatees 
have been documented to respond to approaching boats in an apparent flight response (Nowacek et al. 2004), which can include swimming into deeper water. In shallow water or near the shore, they orient themselves towards deeper water (Nowacek et al. 2004). We noted in Crystal River, Florida, that, when manatees were in the center of the channel as we approached, they would either swim deeper or orient themselves perpendicular to the boat and begin swimming towards the shore. While in Mexico, even in very shallow water and at a distance of $<1 \mathrm{~m}$, manatees would sink to the bottom and maintain their original body orientation. This difference in behavior had an effect on the clarity and distinguishability of the sonar image of the manatee's body. Furthermore, because manatee detection rates may change with distance from the boat, our technique may lend itself well to line transect surveys and distance sampling methods, in a framework similar to that used for estimating the abundance of other marine mammals if the appropriate assumptions are met (see Buckland et al. 1993, Thomas et al. 2002, Barlow 2006).

Experience in interpreting acoustic reflectivity and side-scan images will clearly influence manatee detection. In Florida, the same observer was used in all blind transects, whereas in Mexico, driver and observer alternated positions. The density of manatees was much lower in Laguna de las Ilusiones, and manatees stood out clearly from the sandy bottom substrate. In addition, the water surface in Mexico was very calm. These 2 differences may explain the slightly higher detection rate in Mexico.

Like other manatee detection techniques, the use of side-scan sonar has several limitations (Table 4). One of the major limitations compared to aerial surveys is the small spatial area that is covered. Image interpretation takes some experience and can be a source for error. While no false positives were made during our trials, to the untrained eye it is theoretically possible to confuse a log or sand bank for a manatee. In contrast, we did have several false negatives (where we did not detect the animal even though we clearly passed alongside it). One major limitation compared to visual point surveys and non-motorized boat surveys is the noise of the boat motor. Because these surveys must be done at a constant speed and in a linear fashion, very narrow, meandering rivers could be a challenge. In addition, much like during any kind of motorized transect, manatees may move out of the detection area avoiding the sound of the boat motor in lagoons and rivers wider than the detection range.

In conclusion, the present study demonstrates the use of linear side-scan sonar to detect manatees in the wild. It also demonstrates the applicability of this technique under most environmental conditions tested, in shallow waterways, and at frequencies above the known hearing range of manatees. Preliminary detection rates using the sonar ranged from 81 to $93 \%$ in areas where it was possible to see all or most available manatees.

Having a system that can detect manatees reliably in turbid and tannin-stained waters provides scientists and wildlife managers with a valuable tool, especially those working with manatees in freshwater habitats. Throughout most of the ranges of all extant trichechids, scientists and managers have limited information regarding the areas preferred by manatees and their relative abundances, due to detection difficulties. Although other reasons exist for this lack of information (e.g. lack of adequate funding and capacity), providing better insights into preferred areas and relative abundances would supplement existing data on the species and help identify key locations to monitor and protect.

Side-scan sonar units are now available that are relatively affordable (1000 to 3000 USD), compared to commercial units (ranging from 10000 to 100000 USD)

Table 4. Advantages and disadvantages of using side-scan sonar as a detection technique for free-ranging manatees Trichechus manatus

\begin{tabular}{ll} 
Advantages & Disadvantages and limitations \\
\hline $\begin{array}{l}\text { High detection rate }(>80 \%) \text { within the lateral range of the } \\
\text { sonar beam }\end{array}$ & Small spatial scale surveys \\
Reduced availability bias ${ }^{\mathrm{a}}$ & Limited to detection range of sonar $(<20 \mathrm{~m}$ on each side) \\
$\begin{array}{l}\text { Survey at any time of day (not light dependant) } \\
\text { Additional data along with detection (i.e. coordinates, time, } \\
\text { date, water depth and temperature, bottom substrate type) }\end{array}$ & $\begin{array}{c}\text { Limited to line transects at constant speed } \\
\text { (perception bias) }\end{array}$ \\
$\begin{array}{l}\text { Unit is relatively cheap and can be shared among groups and } \\
\text { countries }\end{array}$ & $\begin{array}{c}\text { Potential for manatees to move from sonar range due } \\
\text { to boat motor noise }\end{array}$ \\
$\begin{array}{c}\text { Only perpendicular detection relative to transect line } \\
\text { aDefined by Marsh \& Sinclair (1989) as the proportion of animals that are unavailable to observers because of water turbidity }\end{array}$
\end{tabular}


and to the costs of aerial surveys, making them an ideal option for small conservation groups. Furthermore, these units also provide important synoptic data for manatee encounters, providing a new method of characterizing manatee habitat in ways not previously possible. With this tool, scientists can determine parameters, which can be important variables that might influence how manatees use their habitat (Table 4).

While this technique provides several advantages over visual boat and aerial surveys, it also has several disadvantages and limitations that should be carefully reviewed when deciding whether it should be employed (Table 4). Ultimately, the survey technique used should reflect a compromise between the study objectives, habitat type, scale, and resources available for the study. Combining 2 or more survey techniques (i.e. side-scan sonar and visual boat surveys) might be the best option in some cases.

Our side-scan sonar method may also be useful for detecting and counting other large endangered aquatic vertebrate fauna in opaque waters (i.e. sea turtles, river dolphins, sturgeons, dugongs, sharks, pigmy hippopotamus). We recommend that careful experiments to determine the usefulness of the method in detecting those species be conducted.

Acknowledgements. Funding for the sonar unit, travel, and lodging for D.G.S. was provided by an ESSE 21 grant from NASA awarded to R.E.F. M. Gibson of Johnson Outdoors was instrumental in purchasing the sonar unit and installing the image-capture software. We thank J. Carcamo, J. Paz, and J. Herrero for lodging and boat use in Honduras. We thank R. Bonde, M. Marmontel, and J. Reid for assistance with the sonar installation, boat use, and data collection in Florida. Work in Mexico was supported by the research project PROMEP/103.5/04/2582 under Federal Permit SGPA/DGVS/ 04466/05 issued to L.D.O.G. We gratefully acknowledge J. Jaffe, D. Johnston, J. Linder, and 3 anonymous reviewers for comments on previous drafts of this manuscript. This project formed part of the MSc thesis of D.G.S.

\section{LITERATURE CITED}

Ackerman BB (1995) Aerial surveys of manatees: a summary and progress report. In: O'Shea TJ, Ackerman BB, Percival HF (eds) Population biology of the Florida manatee. Information and Technology Report 1, National Biological Service, Fort Collins, CO, p 13-33

Aragones LV, Jefferson TA, Marsh H (1997) Marine mammal survey techniques applicable in developing countries. Asian Mar Biol 14:15-39

Au WWL (1996) Acoustic reflectivity of a dolphin. J Acoust Soc Am 99:3844-3848

Barlow J (2006) Cetacean abundance in Hawaiian waters estimated from a summer/fall survey in 2002. Mar Mamm Sci 22:446-464

Buckland ST, Anderson DR, Burnham KP, Laake JL (1993) Distance sampling: estimating abundance of biological populations. Chapman \& Hall, London
Craig BA, Reynolds JE III (2004) Determination of manatee population trends along the Atlantic coast of Florida using a Bayesian approach with temperature-adjusted aerial survey data. Mar Mamm Sci 20:386-400

> De Robertis A, Schell C, Jaffe JS (2003) Acoustic observations of the swimming behavior of the euphausiid Euphausia pacifica Hansen. ICES J Mar Sci 60:885-898

Dickerson DD, Reine KJ, Newton JC, Dickerson CE Jr (1996) Evaluation of hydroacoustic techniques for detecting manatees at water control structures. US Army Engineer District, Jacksonville, FL

Dura E, Bell J, Lane D (2004) Reconstruction of textured seafloors from side-scan sonar images. IEE Proc, Radar Sonar Navig 151:114-126

Garrott RA, Ackerman BB, Cary JR, Heisey DM, Reynods JE III, Rose PM, Wilcox JR (1994) Trends in counts of Florida manatees at winter aggregation sites. J Wildl Manag 58: 642-654

Gerlotto F, Georgakarakos S, Eriksen PK (2000) The application of multibeam sonar technology for quantitative estimates of fish density in shallow water acoustic surveys. Aquat Living Resour 13:385-393

Gerstein ER, Gerstein L, Forsythe SE, Blue JE (1999) The underwater audiogram of the West Indian manatee (Trichechus manatus). J Acoust Soc Am 105:3575-3583

Gonzalez-Socoloske D (2007) Status and distribution of manatees in Honduras and the use of side-scan sonar. MSc thesis, Loma Linda University, CA

Hartman DS (1979) Ecology and behavior of the manatee (Trichechus manatus) in Florida. Am Soc Mammalog Spec Publ 5:1-53

> Jaffe JS, Simonet F, Roberts PLD, Bowles AE (2007) Measurement of the acoustic reflectivity of sirenia (Florida manatees) at $171 \mathrm{kHz}$. J Acoust Soc Am 121:158-165

Kenny AJ, Andrulewicz E, Bokuniewicz H, Boyd SE and others (2003) An overview of seabed mapping technologies in the context of marine habitat classification. ICES J Mar Sci 60:411-418

> Kipps EK, McLellan WA, Rommel SA, Pabst DA (2002) Skin density and its influence on buoyancy in the manatee (Trichechus manatus latirostris), harbor porpoise (Phocoena phocoena), and bottlenose dolphin (Tursiops truncatus). Mar Mamm Sci 18:765-778

Kochman HI, Rathbun GB, Powell JA (1985) Temporal and spatial-distribution of manatees in Kings Bay, Crystal River, Florida. J Wildl Manag 49:921-924

Langtimm CA, O'Shea TJ, Pradel R, Beck CA (1998) Estimates of annual survival probabilities for adult Florida manatees (Trichechus manatus latirostris). Ecology 79: 981-997

Lefebvre LW, Ackerman BB, Portier KM, Pollock KH (1995) Aerial survey as a technique for estimating trends in manatee population size - problems and prospects. In: O'Shea TJ, Ackerman BB, Percival HF (eds) Population biology of the Florida manatee. Information and Technology Report 1, National Biological Service, Fort Collins, CO, p 63-74

Lefebvre LW, Reid JP, Kenworthy WJ, Powell JA (2000) Characterizing manatee habitat use and seagrass grazing in Florida and Puerto Rico: implications for conservation and management. Pac Conserv Biol 5:289-298

> Marsh H, Sinclair DF (1989) Correcting for visibility bias in strip transect aerial surveys of aquatic fauna. J Wildl Manag 53:1017-1024

Miller JH, Potter DC (2001) Active high frequency phasedarray sonar for whale shipstrike avoidance: target strength measurements. In: Holland RC (ed) Oceans. Marine Technology Society, Washington, DC, p 2104-2107 
Miller JH, Potter DC, Weber T, Felix J (1999) The target strength of the northern right whale (Eubalaena glacialis). J Acoust Soc Am 105:992

Morales-Vela B, Olivera-Gomez D, Reynolds JE III, Rathbun GB (2000) Distribution and habitat use by manatees (Trichechus manatus manatus) in Belize and Chetumal Bay, Mexico. Biol Conserv 95:67-75

Nowacek SM, Wells RS, Owen ECG, Speakman TR, Flamm RO, Nowacek DP (2004) Florida manatees, Trichechus manatus latirostris, respond to approaching vessels. Biol Conserv 119:517-523

Rathbun GB, Powell JA, Cruz G (1983) Status of the WestIndian manatee in Honduras. Biol Conserv 26:301-308

Reep RL, Bonde RK (2006) The Florida manatee: biology and

Editorial responsibility: Helene Marsh,

Townsville, Queensland, Australia conservation. University Press of Florida, Gainesville, FL Reynolds JE III, Powell JA (2002) Manatees. In: Perrin WF, Wursig B, Thewissen JGM (eds) Encyclopedia of marine mammals. Academic Press, San Diego, CA, p 709-720

Rommel S, Reynolds JE III (2000) Diaphragm structure and function in the Florida manatee (Trichechus manatus latirostris). Anat Rec 259:41-51

Rose CS, Stoner AW, Matteson K (2005) Use of high-frequency imaging sonar to observe fish behaviour near baited fishing gears. Fish Res 76:291-304

Thomas L, Buckland ST, Burnham KP, Anderson DR, Laake JL, Borchers DL, Strindberg S (2002) Distance sampling. In: El-Shaarawi AH, Piegorsch WW (eds) Encyclopedia of environmetrics. John Wiley \& Sons, Chichester, p 544-552

Submitted: December 5, 2008; Accepted: August 28, 2009

Proofs received from author(s): October 12, 2009 